\title{
Fator pH e Inibição da Produção de Esporos de Fungos Toxigênicos em Co-Cultivo com Leveduras
}

\author{
Mariana Lino de Souza (I), Maria Luiza Queiroz Beti (I), Luís \\ Roberto Batista (II), Whasley Ferreira Duarte (I), Cristina Ferreira \\ Silva (I) \\ (I) UFLA - Universidade Federal de Lavras (DBI; PPG-Microbiologia Agrícola ,Lavras-MG; \\ CEP:37200-000; telefone(35) 38291613), (II) UFLA - Universidade Federal de Lavras \\ (Departamento de Ciências dos Alimentos(DCA), Lavras-MG; CEP:37200-000)
}

\section{Resumo}

Produtos agrícolas, com expressão para a economia brasileira, como frutos, grãos de café, uvas, dentre outros podem ser contaminados por fungos filamentosos produtores de Ocratoxina A (OTA) desde a lavoura até o armazenamento. Essa micotoxina é considerada uma das mais prejudiciais para a saúde humana devido a sua toxicidade. O uso excessivo de fungicidas e os riscos à saúde humana têm levado a pesquisas sobre formas alternativas como o controle biológico. Neste contexto, objetivou-se avaliar o potencial antagônico de 32 cepas de leveduras pertencentes aos gêneros Debaryomyces, Pichia e Saccharomyces, isoladas de frutos do café e do cacau, em co-cultivo com Aspergillus ochraceus e A. carbonarius. As leveduras foram inoculadas $\left(10^{4}\right.$ e $10^{7}$ células $\left./ \mathrm{mL}\right)$ com três isolados de fungos filamentosos, A. carbonarius (isolado 2 e 8CSP3-25), isolados da uva e A. ochraceus SCM 1.9, isolado do café ( $10^{5}$ esporos $\left./ \mathrm{mL}\right)$. Realizouse avaliação do $\mathrm{pH}$, dos cultivos nos meios MEA, e nos meios CYA e YES, em 0,98, 0,96 e 0,94 de $\mathrm{a}_{\mathrm{w}}$, todos foram avaliados após 7 dias de incubação a $28^{\circ} \mathrm{C}$. Essa medição foi realizada colocando uma tira de papel de indicador de pH, da marca FUSION Universal (pH 0-14). Logo em seguida, foi realizada a comparação da coloração obtida com a escala do respectivo papel indicador do $\mathrm{pH}$. Observou-se diferença no crescimento e produção de esporos de Aspergillus carbonarius 2 ( $10^{5}$ células $\left./ \mathrm{mL}\right)$ cocultivado comPichia burtoniiUFLA CF605 em pH 2 e em pH 4. Ambos os

\footnotetext{
Referência:

Mariana Lino de Souza, Maria Luiza Queiroz Beti, Luís Roberto Batista, Whasley Ferreira Duarte, Cristina Ferreira Silva .Fator Ph e Inibição da Produção de Esporos de Fungos Toxigênicos em Co-Cultivo com Leveduras. In: Anais do 12은 Congresso Latinoamericano de Microbiologia e Higiene de Alimentos - MICROAL 2014 [= Blucher Food Science Proceedings, num.1, vol.1]. São Paulo: Editora Blucher, 2014. 
cultivos foram feitos com os mesmos isolados, no mesmo meio de cultivo, MEA com o $\mathrm{pH}$ ajustado para 5,6, porém o isolado de levedura foi cultivado tendo concentração de células de $10^{4}$ células $/ \mathrm{mL}$ e $10^{7}$ células/mL. A diferença na concentração de células do antagonista foi suficiente para alterar o $\mathrm{pH}$ do meio de cultura e consequentemente interferiu no crescimento e produção de esporos do isolado fúngico. Percebeu-se, portanto, que quandoPichia burtonii UFLA CF605 foi utilizado na concentração de $10^{7}$ células $/ \mathrm{mL}$, houve um melhor efeito inibitório sobre o crescimento e a esporulação deste fungo. Concluiu-se que leveduras em co-cultivo com fungos filamentosos são capazes de inibir a produção de esporos,e assim potencialmente diminuir a disseminação destes fungos no processamento de qualquer tipo de produto agrícola e consequentemente a contaminação dos alimentos com micotoxinas, como a Ocratoxina A.

Palavras-Chave: Biocontrole, Debaryomyces, Ocratoxina A, Aspergillus, Pichia

Agência de Fomento: CAPES, FAPEMIG, CNPq 